\title{
Credibility, Accuracy, and Comprehensiveness of Internet-Based Information About Low Back Pain: A Systematic Review
}

Giovanni Ferreira*, MPhil; Adrian C Traeger ${ }^{*}, \mathrm{PhD}$; Gustavo Machado*, PhD; Mary O'Keeffe ${ }^{*}$ PhD; Christopher G Maher*, DSc

Institute for Musculoskeletal Health, Sydney School of Public Health, Faculty of Medicine and Health, The University of Sydney, Sydney, Australia

${ }^{*}$ all authors contributed equally

\section{Corresponding Author:}

Giovanni Ferreira, MPhil

Institute for Musculoskeletal Health, Sydney School of Public Health, Faculty of Medicine and Health

The University of Sydney

Level 10 North, King George V Building

Sydney, 2050

Australia

Phone: 610286279961

Email: giovanni.ferreira@sydney.edu.au

\begin{abstract}
Background: Low back pain (LBP) affects millions of people worldwide, and misconceptions about effective treatment options for this condition are very common. Websites sponsored by organizations recognized as trustworthy by the public, such as government agencies, hospitals, universities, professional associations, health care organizations and consumer organizations are an important source of health information for many people. However, the content of these websites regarding treatment recommendations for LBP has not been fully evaluated.
\end{abstract}

Objective: This study aimed to determine the credibility, accuracy, and comprehensiveness of treatment recommendations for LBP in noncommercial, freely accessible websites.

Methods: We conducted a systematic review of websites from government agencies, hospitals, universities, professional associations, health care organizations and consumer organizations. We conducted searches on Google. Treatment recommendations were coded based on the 2016 National Institute for Health and Care Excellence (NICE) guidelines and the 2017 American College of Physicians guideline on LBP. Primary outcomes were credibility of the website (4-item Journal of the American Medical Association benchmark), accuracy (proportion of website treatment recommendations that were appropriate), and comprehensiveness of website treatment recommendations (proportion of guideline treatment recommendations that were appropriately covered by a website).

Results: We included 79 websites from 6 English-speaking countries. In terms of credibility, 31\% (25/79) of the websites clearly disclosed that they had been updated after the publication of the NICE guidelines. Only 43.28\% (487/1125) website treatment recommendations were judged as accurate. Comprehensiveness of treatment recommendations correctly covered by websites was very low across all types of LBP. For acute LBP, an average of $28 \%(4 / 14)$ guideline recommendations were correctly covered by websites. Websites for radicular LBP were the least comprehensive, correctly covering an average of $16 \%(2.3 / 14)$ recommendations.

Conclusions: Noncommercial freely accessible websites demonstrated low credibility standards, provided mostly inaccurate information, and lacked comprehensiveness across all types of LBP.

(J Med Internet Res 2019;21(5):e13357) doi: 10.2196/13357

\section{KEYWORDS}

medical informatics; low back pain; patient portals; systematic review; consumer health information 


\section{Introduction}

\section{Background}

Low back pain (LBP) is the condition that accounts for the greatest burden of disability worldwide [1]. The global burden of LBP is expected to rise with an ageing population, leading to increased pressure on health systems [2]. The literature on LBP is vast, with a considerable amount of evidence on risk factors [3], prognosis [4], and effectiveness of treatment for LBP $[5,6]$. However, misconceptions in the general population and among health professionals [7] about LBP are very common $[8,9]$. A possible solution to reduce the inconsistency between beliefs of the general public and evidence-based information is to disseminate appropriate information through easily accessible means, such as the internet.

The internet has rapidly become an important source of health information [10]. In fact, there is evidence that more people seek health information first on the internet than with health care providers [11]. Recent data indicate that 78\% [12] of Australians and $61 \%$ of people in the United Kingdom [13] used the internet to obtain health information in the previous 12 months [12,13]. People engaging with internet-based health information do so for several reasons, including making treatment decisions, supplementing information provided by a health professional, and self-managing a health condition [14]. The ready availability of internet-based health information may have both favorable and unfavorable consequences: although it empowers people to actively participate in their health care, the poor quality of information across many health conditions [15-17] calls into question its usefulness.

Government agencies and health care and professional organizations now sponsor websites containing health information for a broad range of health topics, including LBP. Websites hosted by those organizations are usually seen as more credible than other sources of internet-based information for people with LBP [18]. Previous studies examining the content of internet-based information about LBP have limitations, such as investigating limited samples and including websites with commercial purposes [19-21].

\section{Objectives}

Our objective was to assess the credibility, accuracy, and comprehensiveness of treatment recommendations for LBP given by websites sponsored by sources typically recognized as trustworthy by the public.

\section{Methods}

\section{Eligibility Criteria}

We reported this review following guidance provided by the Preferred Reporting Items for Systematic Reviews and Meta-Analyses guidelines where possible [22]. We identified trustworthy websites to be those from government agencies, nonprofit nongovernmental organizations, hospitals, professional societies, universities, and consumer organizations. We sought websites from 6 major English-speaking countries: Australia, Canada, New Zealand, South Africa, the United Kingdom, and the United States. Websites had to present content about treatments for either acute, persistent, or radicular LBP. Websites that had links to other forms of content presentation, such as booklets, leaflets, or brochures, were also included. We excluded websites published in languages other than English, websites only containing information about aspects other than treatment of LBP (eg, anatomy of the lumbar spine), and those requiring any type of password or membership. We excluded websites that did not provide at least 1 clear recommendation for either acute, persistent, or radicular LBP.

\section{Search Strategy}

We used Google to search for noncommercial freely accessible websites presenting LBP information. We conducted searches on 5 February and updated it on July 20, 2018. We used Google AdWords to identify the most popular terms on Google related to LBP worldwide. To increase search specificity, we conducted searches on each country's dedicated Google website (Multimedia Appendix 1). Furthermore, 1 researcher (GF) performed the initial screening of websites using the Google Chrome Web browser. Before starting every new search, we cleared the browsing data. We screened the first 50 records from each search by looking at titles, snippets that followed each title, and URLs for each retrieved Web page. All links deemed relevant by the first reviewer were collated to a Microsoft Excel sheet and then screened for eligibility by 1 of the 3 independent reviewers (AT, CM, and GM), with all discrepancies resolved by discussion.

\section{Data Extraction and Coding}

A reviewer (GF) extracted data into a spreadsheet and 1 of the 3 other reviewers (AT, GM, and MOK) cross-checked the data. We extracted information on characteristics of the website, such as the host, country, and type of LBP covered. Websites treatment recommendations were coded according to the recommendations from the 2016 National Institute for Health and Care Excellence (NICE) guidelines [5] and the 2017 American College of Physicians [6] guidelines for the management of LBP with or without sciatica. Furthermore, 3 authors (GF, AT, and CM) coded each guideline recommendation as having been (1) endorsed by at least 1 guideline; (2) dismissed by at least 1 guideline; and (3) subject to conflicting positions between the 2 guidelines. The accuracy of treatment recommendations given by websites was judged by concordance with the guideline recommendations and coded as follows:

- Appropriate endorsement: A recommendation given by a website to use a treatment that was endorsed by at least 1 guideline.

- Appropriate dismissal: A recommendation given by a website to avoid a treatment that was dismissed by at least 1 guideline.

- Inappropriate endorsement: A recommendation given by a website to use a treatment that was dismissed by at least 1 guideline.

- Inappropriate dismissal: A recommendation given by a website to avoid a treatment that was endorsed by at least 1 guideline. 
- Endorsed: A recommendation given by a website to use a treatment that was not mentioned in either guideline.

- Dismissed: A recommendation given by a website to avoid a treatment that was not mentioned in either guideline.

- Unclear: A recommendation given by a website that was not clearly targeted to a specific LBP condition (eg, a recommendation to use skeletal muscle relaxants for LBP) or when a recommendation was vague in the description of the treatment (eg, spinal injections rather than epidural corticosteroid injection or facet joint corticosteroid injection).

\section{Outcomes}

Our primary outcomes were credibility, accuracy, and comprehensiveness of each website.

Credibility: We used the 4-item Journal of the American Medical Association (JAMA) benchmark [23] to assess the credibility of each website. The JAMA benchmark addresses 4 elements: (1) currency of information, (2) declaration of authorship, (3) presentation of a list of references, and (4) disclosure of any conflict of interest, funding, or sponsorship. Each item was categorized as yes, no, or not reported. We considered a website to be up-to-date if its date of publication or last update had been subsequent to the publication date of the 2016 NICE guidelines [5]. We considered authorship to be declared when single or multiple authors were listed or when authorship was attributed to a working group or an entity.

Accuracy: We defined accuracy as the number and proportion of website recommendations that were judged clear and accurate. Accurate recommendations were those coded as being appropriate endorsements, appropriate dismissals, and treatments dismissed by the website and not listed in either guideline. Inaccurate recommendations were those coded as being inappropriate endorsements, inappropriate dismissals, and treatments endorsed by the website but not listed in either guideline.

Comprehensiveness: We defined comprehensiveness as the number and proportion of guideline recommendations that were appropriately covered by a website. The comprehensiveness of a website was given by the ratio between the sum of appropriate endorsements and dismissals and the total number of recommendations in the guidelines for each different type of LBP.

\section{Data Analysis}

We presented data for acute, persistent, and radicular LBP separately. We used descriptive statistics to summarize credibility, accuracy, and comprehensiveness across the websites. Each item of the JAMA benchmark was presented individually. Data on accuracy were presented as the number and proportion of clear accurate recommendations, the number of clear accurate recommendations to use a treatment, and the number of clear accurate recommendations to avoid a treatment. Data on comprehensiveness were presented as the mean (SD) number of guideline recommendations correctly covered by websites and as the average proportion of website recommendations, as well as the mean (SD) number of guideline recommendations correctly covered by websites to use and to avoid a treatment.

\section{Results}

\section{Selected Websites}

We conducted 72 searches on Google, resulting in 3600 records to be screened. We excluded 3434 records by reading the titles on Google and retained 166 websites for eligibility assessment. Among these, 87 were ineligible. We, therefore, included 79 unique websites. As some websites had information for more than 1 type of LBP, a total of 123 Web pages were included in the final analysis (Figure 1).

Figure 1. Study flow diagram.

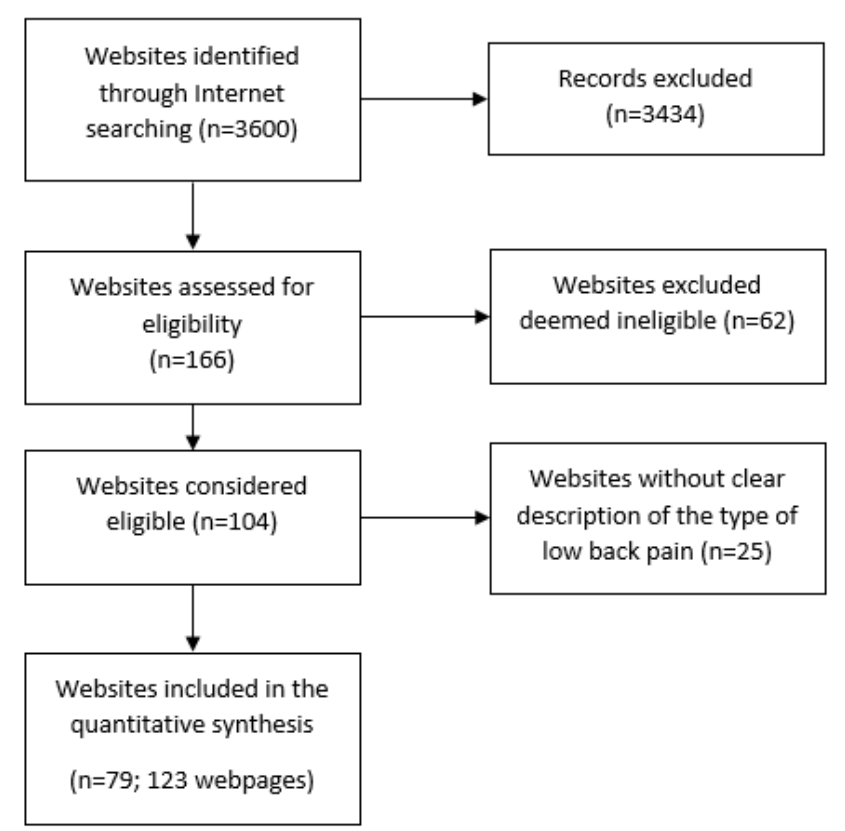




\section{Characteristics of the Included Websites}

Table 1 outlines the characteristics of the included websites. $53 \%(42 / 79)$ of the websites were from the United States, $24 \%$ (19/79) were from the United Kingdom, 17\% (13/79) were from Australia, 4\% (3/79) were from Canada, 1\% (1/79) were from New Zealand, and 1\% (1/79) were from South Africa. $43 \%$ (34/79) of websites were owned by hospitals, followed by websites from government agencies, which represented $25 \%$ (20/79) of websites. More information about the included websites is shown in Multimedia Appendix 2. Detailed information about the treatments covered by the websites is listed in Multimedia Appendix 3 to Multimedia Appendix 6.

\section{Credibility of Websites}

A total of 43 websites $(54.4 \%, 43 / 79)$ disclosed their creation date or last update, and only $25(31 \%, 25 / 79)$ of these websites had been updated after the publication of the NICE guidelines. Only $18(22 \%, 18 / 79)$ websites provided a declaration of authorship. Only $21(26 \%, 21 / 79)$ websites presented a list of references. Disclosure of any potential conflict of interest, funding source, or any form of sponsorship was only provided by $5(6 \%, 5 / 79)$ websites (Table 1$)$. Details on the assessment of credibility are shown in Multimedia Appendix 2. 
Table 1. Characteristics of websites and credibility data $(\mathrm{N}=79)$.

\begin{tabular}{|c|c|}
\hline Descriptive and credibility variables & Statistics, n (\%) \\
\hline \multicolumn{2}{|l|}{ Country } \\
\hline Australia & $13(16.4)$ \\
\hline Canada & $3(3.8)$ \\
\hline New Zealand & $1(1.2)$ \\
\hline South Africa & $1(1.2)$ \\
\hline United Kingdom & $19(24.1)$ \\
\hline United States & $42(53.3)$ \\
\hline \multicolumn{2}{|l|}{ Type of website } \\
\hline Consumer organization & $2(2.5)$ \\
\hline Government & $20(25.3)$ \\
\hline Hospital & $34(43.0)$ \\
\hline Nongovernmental organization & $8(10.1)$ \\
\hline Professional association or society & $8(10.1)$ \\
\hline University & $7(8.8)$ \\
\hline \multicolumn{2}{|l|}{ Type of low back pain ${ }^{a}$} \\
\hline Acute & $55(69.6)$ \\
\hline Persistent & $29(36.7)$ \\
\hline Radicular & $39(49.3)$ \\
\hline \multicolumn{2}{|c|}{ Updated after 2016 National Institute for Health and Care Excellence guidelines } \\
\hline No & $19(24.1)$ \\
\hline Yes & $25(31.6)$ \\
\hline Not reported & $35(44.3)$ \\
\hline \multicolumn{2}{|l|}{ Declaration of authorship } \\
\hline No & $61(77.2)$ \\
\hline Yes & $18(22.8)$ \\
\hline \multicolumn{2}{|l|}{ List of references } \\
\hline No & $58(73.4)$ \\
\hline Yes & $21(26.6)$ \\
\hline \multicolumn{2}{|c|}{ Disclosure of any conflict of interest, funding, or sponsorship } \\
\hline Yes & $5(6.3)$ \\
\hline Not reported & $74(93.7)$ \\
\hline
\end{tabular}

${ }^{\mathrm{a}}$ The total is greater than 79 as some websites presented information for more than 1 type of low back pain (LBP).

Table 2. Accuracy of website treatment recommendations.

\begin{tabular}{llllll}
\hline Condition & $\begin{array}{l}\text { Number of recommen- } \\
\text { dations }\end{array}$ & $\begin{array}{l}\text { Number of unclear rec- } \\
\text { ommendations, } \mathrm{n}(\%)\end{array}$ & $\begin{array}{l}\text { Number of accurate } \\
\text { recommendations, } \mathrm{n} \\
(\%)\end{array}$ & $\begin{array}{l}\text { Number of clear accu- } \\
\text { rate recommendations } \\
\text { to use a treatment, } \mathrm{n} \\
(\%)\end{array}$ & $\begin{array}{l}\text { Number of clear accu- } \\
\text { rate recommendations } \\
\text { to avoid a treatment, } \mathrm{n} \\
(\%)\end{array}$ \\
\hline Acute LBP & 452 & $98(21.7)$ & $228(50.4)$ & $187(61.7)$ & $41(80.3)$ \\
Persistent LBP & 402 & $105(26.1)$ & $154(38.3)$ & $116(45.8)$ & $38(86.3)$ \\
Radicular LBP & 271 & $28(10.3)$ & $105(38.7)$ & $86(38.7)$ & $17(84.4)$ \\
Total & 1125 & $231(20.53)$ & $487(43.28)$ & $389(50.00)$ & $96(82.7)$ \\
\hline
\end{tabular}


Table 3. Comprehensiveness of website treatment recommendations. Recommendations that were conflicting between guidelines were not included in the assessment of comprehensiveness.

\begin{tabular}{lllll}
\hline Condition & $\begin{array}{l}\text { Number of recom- } \\
\text { mendations in the } \\
\text { guidelines }\end{array}$ & $\begin{array}{l}\text { Guideline recommendations cor- } \\
\text { rectly covered by websites, mean } \\
\text { (SD; percentage of total number } \\
\text { of recommendations in guidelines) }\end{array}$ & $\begin{array}{l}\text { Guideline recommendations to use } \\
\text { atreatment correctly covered by } \\
\text { websites, mean (SD; percentage } \\
\text { of total number of recommenda- } \\
\text { tions in guidelines) }\end{array}$ & $\begin{array}{l}\text { Guideline recommendations to } \\
\text { eved bebsites, mean } \text { (SD; per- } \\
\text { centage of total number of recom- } \\
\text { mendations in guidelines) }\end{array}$ \\
\hline Acute LBP & 14 & $4.0(1.5 ; 28.6)$ & $3.4(1.3 ; 24.3)$ & $0.6(0.6 ; 4.3)$ \\
Persistent LBP & 25 & $4.5(2.8 ; 18.0)$ & $4.0(2.3 ; 16.0)$ & $0.5(1.1 ; 2.0)$ \\
Radicular LBP & 14 & $2.3(1.9 ; 16.4)$ & $2.2(1.9 ; 15.7)$ & $0.1(0.3 ; 0.7)$ \\
\hline
\end{tabular}

${ }^{a}$ LBP: low back pain.

\section{Accuracy of Website Recommendations}

Data for accuracy are presented in Table 2. In total, websites provided 1125 recommendations, with 487 (43.3\%) being accurate, 407 (36.2\%) inaccurate, and 231 (20.5\%) unclear. Websites provided many more recommendations to use rather than to avoid a treatment (778 vs 116). Acute LBP had the highest number of recommendations among all the types of LBP. The proportion of accurate recommendations for acute LBP $(50.4 \%)$ was higher than the proportion of accurate recommendations for persistent LBP (38.3\%) and radicular LBP $(38.7 \%)$. Advice to stay active was the most common treatment recommendation given by websites for acute LBP, having been endorsed by 45 out of 55 (81\%) websites. Moreover, 28 out of $55(50 \%)$ websites inappropriately endorsed paracetamol for acute LBP, and 6 out of 29 (20\%) websites inappropriately endorsed opioids for persistent LBP (Multimedia Appendices 3-5).

\section{Comprehensiveness of Website Recommendations}

Details on the comprehensiveness of website recommendations are shown in Table 3. The proportion of guideline recommendations correctly covered by websites was higher for acute LBP (28.6\%) compared with persistent LBP (18.0\%) and radicular LBP (16.4\%). Websites for radicular LBP were the least comprehensive, covering on average 2.3 (1.9) guideline recommendations. Across all types of LBP, the most comprehensive websites correctly covered only about $50 \%$ of the guideline recommendations-see Multimedia Appendix 6.

\section{Discussion}

\section{Principal Findings}

Treatment recommendations for LBP in websites from trustworthy sources failed to meet our benchmarks for credibility, provided a high proportion of inaccurate or unclear recommendations, and lacked comprehensiveness. In general, websites did not provide adequate resources for people to independently verify the truthfulness of the information provided. The accuracy of treatment recommendations was generally low across all different types of LBP. The lack of comprehensiveness across all websites was even more pronounced when covering guideline recommendations to avoid an ineffective treatment.

\section{Comparison With Previous Work}

Previous research had surveyed the accuracy of information only for a specific type of LBP (eg, acute LBP) [20], had not distinguished between types of LBP when analyzing recommendations from guidelines [19,21], and examined a limited sample of websites [19-21,24], including commercial websites [19,21]. We presented results for acute, persistent, and radicular LBP separately, given that some treatments known to be effective for 1 type of LBP might be ineffective for another or evidence might be currently lacking or be of questionable quality. That is the case for skeletal muscle relaxants, where evidence supports their use for acute LBP but benefits for persistent and radicular LBP are still uncertain [25].

In contrast to previous studies [19-21,26], we surveyed only websites from sources recognized as trustworthy by patients with LBP [18], such as government agencies, health care organizations, and universities. On the basis of the findings of previous studies showing that commercial websites were mostly of poor quality [19,21], our a priori hypothesis was that noncommercial freely accessible websites would have more comprehensive and accurate information compared with commercial websites $[19,21]$. This was not the case for many guideline-endorsed treatments. For example, although advice to stay active was recommended for acute LBP by $81 \%(45 / 55)$ of the websites, only $41 \%(12 / 29)$ and $46 \%$ (18/39) of websites recommended it for radicular and persistent LBP, respectively. Our findings suggest that websites of trusted sources are failing not only at conveying the accurate message on the benefits of guideline-endorsed [5,6] and first-line treatment [27] recommendations but also at dismissing ineffective treatment options such as bed rest for acute LBP, for which evidence on its ineffectiveness has long been known [28].

The large number of recommendations that were inaccurate and unclear found in our review supports findings from previous studies that people cannot obtain appropriate information about LBP on the internet [18]. For example, more than half of all treatment recommendations given by websites in our review were either inaccurate or unclear, which risks misleading the public [29]. In addition, evidence from the general population suggests that seeking health-related information on the internet is associated with increased health care utilization [30-32]. The fact that people often seek health information on the internet for LBP combined with the large amount of inaccurate and unclear information contained in these websites can potentially be driving people to seek unnecessary or ineffective care. On 
the contrary, credible and accurate internet-based information may contribute to reducing health care utilization. A recent study has attributed a $12 \%$ decrease in overall health care utilization, including LBP, to the launching of a website containing guideline-endorsed information maintained by the Dutch College of General Practitioners [33]. If one of the goals of internet-based health information is to reduce unnecessary consultations in primary care [33], these sources of internet-based information about LBP must provide patients the necessary means to make informed decisions about their health care. For this to happen, improving the credibility standards, as well as providing accurate and comprehensive treatment recommendations is necessary. When recommending treatments for LBP, websites must rely extensively on the evidence provided by high-quality clinical practice guidelines such as the NICE guidelines [5] and American College of Physicians [6] guidelines.

\section{Limitations}

The strengths of this study include using Google AdWords to develop search terms individuals actually use to find internet-based information about treatments for LBP. Searching the first 50 records of each search can also be considered a strength, as people searching for internet-based information usually do not look past the 10 or 20 first hits [34]. One potential limitation of our study was the use of Google as the sole Web browser to screen for websites. Nevertheless, our choice was based on the fact that Google is the most used search engine worldwide, Google has the best search validity (ie, returns links to websites that can be opened), and results from other engines usually highly overlap with those from Google [34]. Another limitation involves a very small number of inconsistencies (3 recommendations out of a total of $56,5 \%$ ) between the 2 guidelines. Nevertheless, that likely represents the uncertainty around the evidence for treatments for which there is currently no consensus, such as acupuncture [35]. We dealt with this limitation by choosing a more conservative approach and classified all endorsements and dismissals of treatments with inconsistent recommendations as being inappropriate.

\section{Conclusions}

Websites from government agencies, consumer organizations, hospitals, nongovernmental organizations, professional associations, and universities demonstrated low credibility standards, provided mostly inaccurate information, and lacked comprehensiveness across all types of LBP. Our findings highlight the need for these organizations to reformulate their treatment recommendations to reflect current evidence in the management of LBP.

\section{Acknowledgments}

GF is supported by CAPES (Coordenação de Aperfeiçoamento de Pessoal de Nível Superior), Brazil, with a PhD scholarship. AT is supported by an National Health and Medical Research Council (NHMRC) Early Career Fellowship. GM is supported by an NHMRC Early Career Fellowship. MOK is supported by a European Commission Horizon 2020 Marie Skłodowska Curie post-doctoral fellowship. CM is supported by an NHMRC Principal Research Fellowship and NHMRC Program Grant.

\section{Authors' Contributions}

The corresponding author (GF) attests that all listed authors meet authorship criteria and that no others meeting the criteria have been omitted.

\section{Conflicts of Interest}

None declared.

\section{Multimedia Appendix 1}

Search terms employed on Google.

[PDF File (Adobe PDF File), 76KB-Multimedia Appendix 1]

\section{Multimedia Appendix 2}

Additional characteristics of the included websites.

[PDF File (Adobe PDF File), 106KB-Multimedia Appendix 2]

\section{Multimedia Appendix 3}

Frequency (\%) of websites endorsing or dismissing treatments mentioned in guidelines for acute low back pain $(\mathrm{N}=55)$.

[DOCX File, 15KB-Multimedia Appendix 3]

\section{Multimedia Appendix 4}

Frequency $(\%)$ of websites endorsing or dismissing treatments mentioned in guidelines for persistent low back pain $(\mathrm{N}=28)$. 
[PDF File (Adobe PDF File), 68KB-Multimedia Appendix 4]

\section{Multimedia Appendix 5}

Frequency (\%) of websites endorsing or dismissing treatments mentioned in guidelines for radicular low back pain $(\mathrm{N}=39)$. [PDF File (Adobe PDF File), 76KB-Multimedia Appendix 5]

\section{Multimedia Appendix 6}

Accuracy and comprehensiveness of website recommendations.

[PDF File (Adobe PDF File), 175KB-Multimedia Appendix 6]

\section{References}

1. GBD 2016 Disease Injury Incidence Prevalence Collaborators. Global, regional, and national incidence, prevalence, and years lived with disability for 328 diseases and injuries for 195 countries, 1990-2016: a systematic analysis for the Global Burden of Disease Study 2016. Lancet 2017 Sep 16;390(10100):1211-1259 [FREE Full text] [doi:

10.1016/S0140-6736(17)32154-2] [Medline: 28919117]

2. Hurwitz EL, Randhawa K, Yu H, Côté P, Haldeman S. The Global Spine Care Initiative: a summary of the global burden of low back and neck pain studies. Eur Spine J 2018 Sep;27(Suppl 6):796-801. [doi: 10.1007/s00586-017-5432-9] [Medline: 29480409]

3. Parreira P, Maher CG, Steffens D, Hancock MJ, Ferreira ML. Risk factors for low back pain and sciatica: an umbrella review. Spine J 2018 Dec;18(9):1715-1721. [doi: 10.1016/j.spinee.2018.05.018] [Medline: 29792997]

4. Costa LD, Maher C, McAuley J, Hancock MJ, Herbert RD, Refshauge KM, et al. Prognosis for patients with chronic low back pain: inception cohort study. Br Med J 2009 Oct 06;339:b3829 [FREE Full text] [doi: 10.1136/bmj.b3829] [Medline: 19808766]

5. National Institute for Health and Care Excellence. National Institute for Health and Care Excellence. Manchester: National Institute for Health and Care Excellence; 2016. Low back pain and sciatica in over 16s: assessment and management URL: https://www.nice.org.uk/guidance/ng59 [accessed 2019-03-11] [WebCite Cache ID 76mpq301K]

6. Qaseem A, Wilt TJ, McLean RM, Forciea MA, Clinical Guidelines Committee of the American College of Physicians. fNoninvasive treatments for acute, subacute, and chronic low back pain: a clinical practice guideline from the American College of Physicians. Ann Intern Med 2017 Apr 04;166(7):514-530. [doi: 10.7326/M16-2367] [Medline: 28192789]

7. Darlow B, Fullen BM, Dean S, Hurley DA, Baxter GD, Dowell A. The association between health care professional attitudes and beliefs and the attitudes and beliefs, clinical management, and outcomes of patients with low back pain: a systematic review. Eur J Pain 2012 Jan;16(1):3-17 [FREE Full text] [doi: 10.1016/j.ejpain.2011.06.006] [Medline: 21719329]

8. Gross DP, Ferrari R, Russell AS, Battié MC, Schopflocher D, Hu RW, et al. A population-based survey of back pain beliefs in Canada. Spine (Phila Pa 1976) 2006 Aug 15;31(18):2142-2145. [doi: 10.1097/01.brs.0000231771.14965.e4] [Medline: 16915103]

9. Klaber Moffett JA, Newbronner E, Waddell G, Croucher K, Spear S. Public perceptions about low back pain and its management: a gap between expectations and reality? Health Expect 2000 Sep;3(3):161-168 [FREE Full text] [Medline: 11281925]

10. Fox S, Duggan M. Pew Research Center. Health Online 2013 URL: http://www.pewinternet.org/2013/01/15/ health-online-2013/ [accessed 2019-03-11] [WebCite Cache ID 1552285578408097]

11. Volkman JE, Luger T, Harvey K, Hogan TP, Shimada SL, Amante D, et al. The National Cancer Institute's Health Information National Trends Survey [HINTS]: a national cross-sectional analysis of talking to your doctor and other healthcare providers for health information. BMC Fam Pract 2014 Jun 06;15:111 [FREE Full text] [doi: 10.1186/1471-2296-15-111] [Medline: 24906558]

12. Public Opinion Polling. Research Australia. Australia Speaks! URL: https://researchaustralia.org/wp-content/uploads/2017/ 08/2017-Opinion-Poll-Digital.pdf [accessed 2019-03-11] [WebCite Cache ID 1552285420363140]

13. TNS Political \& Social. European Comission. 2015 Mar 30. EUROPEAN CITIZENS' DIGITAL HEALTH LITERACY URL: http://ec.europa.eu/commfrontoffice/publicopinion/flash/fl 404 en.pdf [accessed 2019-03-12] [WebCite Cache ID 76oWMtntF]

14. Ramsey I, Corsini N, Peters MD, Eckert M. A rapid review of consumer health information needs and preferences. Patient Educ Couns 2017 Sep;100(9):1634-1642. [doi: 10.1016/j.pec.2017.04.005] [Medline: 28442155]

15. Fisher JH, O'Connor D, Flexman AM, Shapera S, Ryerson CJ. Accuracy and reliability of internet resources for information on idiopathic pulmonary fibrosis. Am J Respir Crit Care Med 2016 Dec 15;194(2):218-225. [doi: 10.1164/rccm.201512-23930C] [Medline: 26849779] 
16. Meric F, Bernstam EV, Mirza NQ, Hunt KK, Ames FC, Ross MI, et al. Breast cancer on the world wide web: cross sectional survey of quality of information and popularity of websites. Br Med J 2002 Mar 09;324(7337):577-581 [FREE Full text] [Medline: 11884322$]$

17. Storino A, Castillo-Angeles M, Watkins AA, Vargas C, Mancias JD, Bullock A, et al. Assessing the accuracy and readability of online health information for patients with pancreatic cancer. JAMA Surg 2016 Dec 01;151(9):831-837. [doi: 10.1001/jamasurg.2016.0730] [Medline: 27144966]

18. Nielsen M, Jull G, Hodges PW. Information needs of people with low back pain for an online resource: a qualitative study of consumer views. Disabil Rehabil 2014;36(13):1085-1091. [doi: 10.3109/09638288.2013.829532] [Medline: 24001260]

19. Butler L, Foster NE. Back pain online: a cross-sectional survey of the quality of web-based information on low back pain. Spine (Phila Pa 1976) 2003 Feb 15;28(4):395-401. [doi: 10.1097/01.BRS.0000048497.38319.D3] [Medline: 12590218]

20. Hendrick PA, Ahmed OH, Bankier SS, Chan TJ, Crawford SA, Ryder CR, et al. Acute low back pain information online: an evaluation of quality, content accuracy and readability of related websites. Man Ther 2012 Aug;17(4):318-324. [doi: 10.1016/j.math.2012.02.019] [Medline: 22464886]

21. Li L, Irvin E, Guzmán J, Bombardier C. Surfing for back pain patients: the nature and quality of back pain information on the Internet. Spine (Phila Pa 1976) 2001 Mar 01;26(5):545-557. [Medline: 11242383]

22. Liberati A, Altman DG, Tetzlaff J, Mulrow C, Gøtzsche PC, Ioannidis JP, et al. The PRISMA statement for reporting systematic reviews and meta-analyses of studies that evaluate healthcare interventions: explanation and elaboration. BMJ 2009 Jul 21;339:b2700 [FREE Full text] [doi: 10.1136/bmj.b2700] [Medline: 19622552]

23. Silberg WM, Lundberg GD, Musacchio RA. Assessing, controlling, and assuring the quality of medical information on the Internet: Caveant lector et viewor--Let the reader and viewer beware. J Am Med Assoc 1997 Apr 16;277(15):1244-1245. [Medline: 9103351]

24. Samanci Y, Celik SE. Low back pain and internet: infopollution. Turk Neurosurg 2017;27(5):804-808 [FREE Full text] [doi: 10.5137/1019-5149.JTN.18521-16.1] [Medline: 27858395]

25. Abdel Shaheed C, Maher CG, Williams KA, McLachlan AJ. Efficacy and tolerability of muscle relaxants for low back pain: systematic review and meta-analysis. Eur J Pain 2017 Dec;21(2):228-237. [doi: 10.1002/ejp.907] [Medline: 27329976]

26. Black NM, Sullivan SJ, Mani R. A biopsychosocial understanding of lower back pain: content analysis of online information. Eur J Pain 2018 Dec;22(4):728-744. [doi: 10.1002/ejp.1158] [Medline: 29280231]

27. Foster NE, Anema JR, Cherkin D, Chou R, Cohen SP, Gross DP, Lancet Low Back Pain Series Working Group. Prevention and treatment of low back pain: evidence, challenges, and promising directions. Lancet 2018 Dec 09;391(10137):2368-2383. [doi: 10.1016/S0140-6736(18)30489-6] [Medline: 29573872]

28. Malmivaara A, Häkkinen U, Aro T, Heinrichs ML, Koskenniemi L, Kuosma E, et al. The treatment of acute low back pain--bed rest, exercises, or ordinary activity? N Engl J Med 1995 Feb 09;332(6):351-355. [doi: 10.1056/NEJM199502093320602] [Medline: 7823996]

29. Benigeri M, Pluye P. Shortcomings of health information on the Internet. Health Promot Int 2003 Dec;18(4):381-386. [Medline: 14695369 ]

30. Hone T, Palladino R, Filippidis FT. Association of searching for health-related information online with self-rated health in the European Union. Eur J Public Health 2016 Dec;26(5):748-753. [doi: 10.1093/eurpub/ckw022] [Medline: 26944894]

31. Suziedelyte A. How does searching for health information on the internet affect individuals' demand for health care services? Soc Sci Med 2012 Nov;75(10):1828-1835. [doi: 10.1016/j.socscimed.2012.07.022] [Medline: 22884947]

32. Ariza M, Guerrisi C, Souty C, Rossignol L, Turbelin C, Hanslik T, et al. Healthcare-seeking behaviour in case of influenza-like illness in the French general population and factors associated with a GP consultation: an observational prospective study. BJGP Open 2018 Jan;1(4):- [FREE Full text] [doi: 10.3399/bjgpopen17X101253] [Medline: 30564694]

33. Spoelman WA, Bonten TN, de Waal MW, Drenthen T, Smeele IJ, Nielen MM, et al. Effect of an evidence-based website on healthcare usage: an interrupted time-series study. BMJ Open 2016 Dec 09;6(11):e013166 [FREE Full text] [doi: 10.1136/bmjopen-2016-013166] [Medline: 28186945]

34. Wang LP, Wang JX, Wang M, Li Y, Liang YC, Xu D. Using internet search engines to obtain medical information: a comparative study. J Med Internet Res 2012 May 16;14(3):e74 [FREE Full text] [doi: 10.2196/jmir.1943] [Medline: 22672889]

35. O'Connell NE, Cook CM, Wand BM, Ward SP. Clinical guidelines for low back pain: a critical review of consensus and inconsistencies across three major guidelines. Best Pract Res Clin Rheumatol 2016 Dec;30(6):968-980. [doi: 10.1016/j.berh.2017.05.001] [Medline: 29103554]

\section{Abbreviations}

JAMA: Journal of the American Medical Association

LBP: low back pain

NICE: National Institute for Health and Care Excellence 
Edited by G Eysenbach; submitted 10.01.19; peer-reviewed by M Rethlefsen, M Thomas; comments to author 27.02.19; revised version received 01.03.19; accepted 03.03.19; published 07.05.19

Please cite as:

Ferreira G, Traeger AC, Machado G, O'Keeffe M, Maher CG

Credibility, Accuracy, and Comprehensiveness of Internet-Based Information About Low Back Pain: A Systematic Review

J Med Internet Res 2019;21(5):e13357

URL: https://www.jmir.org/2019/5/e13357/

doi: $10.2196 / 13357$

PMID: $\underline{31066689}$

(C) Giovanni Ferreira, Adrian C Traeger, Gustavo Machado, Mary O'Keeffe, Christopher G Maher. Originally published in the Journal of Medical Internet Research (http://www.jmir.org), 07.05.2019. This is an open-access article distributed under the terms of the Creative Commons Attribution License (https://creativecommons.org/licenses/by/4.0/), which permits unrestricted use, distribution, and reproduction in any medium, provided the original work, first published in the Journal of Medical Internet Research, is properly cited. The complete bibliographic information, a link to the original publication on http://www.jmir.org/, as well as this copyright and license information must be included. 